\title{
Ischemic Fasciitis
}

National Cancer Institute

\section{Source}

National Cancer Institute. Ischemic Fasciitis. NCI Thesaurus. Code C6483.

A reactive, painless lesion which is characterized by a pseudosarcomatous proliferation of fibroblasts and myofibroblasts usually in the deep subcutaneous tissue. It occurs mainly around the limb girdles, sacral region, and greater trochanter. It affects mainly elderly patients and sometimes is associated with physical immobility. Local excision is usually curative. 